\title{
Viscous Flow Activation Energy Adaptation by Isochronal Spark Plasma Sintering
}

\author{
Tanaji Paul and Sandip P. Harimkar ${ }^{1, *}$ \\ ${ }^{1}$ School of Mechanical and Aerospace Engineering, \\ Oklahoma State University, Stillwater, OK 74078
}

\begin{abstract}
The densification mechanism of amorphous $\mathrm{Fe}_{48} \mathrm{Cr}_{15} \mathrm{Mo}_{14} \mathrm{Y}_{2} \mathrm{C}_{15} \mathrm{~B}_{6}$ alloy powder during isochronal spark plasma sintering was analyzed to determine the innate function of high heating rates. Densification ensued and concluded at gradually lower temperatures while attaining higher maximum rates with increasing heating rates in the first stage. The shrinkage behavior analyzed under the theoretical framework of viscous flow revealed a steady reduction in the activation energy leading to a resultant enhancement of densification rate in the initial stage.
\end{abstract}

Keywords: Bulk metallic glass; Spark plasma sintering; Viscous flow

\footnotetext{
${ }^{*}$ Corresponding author. Tel.: +1 405744 5900; fax: +1 4057447873

E-mail address: sandip.harimkar@okstate.edu (S.P. Harimkar)
} 
Spark plasma sintering (SPS) is an advanced pressure and electric current assisted sintering technique that has garnered widespread popularity due to its versatility to sinter a variety of materials such as metals, ceramics, and composites [1]. Fully dense compacts can be manufactured by SPS at lower temperatures as compared to other pressure assisted sintering techniques such as hot pressing (HP) and hot isostatic pressing (HIP) [2]. Considerable research has been undertaken on the SPS of recently developed Fe based amorphous alloy powders [3-6] in order to utilize their excellent mechanical and electrochemical properties [7]. Joule heating in the powder caused by the applied direct current results in internal heat generation and allows high heating rates during the process $[1,8]$. For example, SPS carried out at a heating rate of 100 ${ }^{\circ} \mathrm{Cmin}^{-1}$ resulted in near full densification within a short cycle time of about $20 \mathrm{~min}$ [9]. Although SPS has been utilized to sinter Fe-based amorphous alloys to full density, most of the reported investigations are experimental studies performed using scattered heating rates in the range of 50-100 ${ }^{\circ} \mathrm{Cmin}^{-1}$ [9-13], and the inherent role of heating rate in the enhancement of densification is not thoroughly established. The present study seeks to analyze the effect of systematic increase in heating rate on the densification characteristics of a recently developed Fe-based amorphous alloy $\left(\mathrm{Fe}_{48} \mathrm{Cr}_{15} \mathrm{Mo}_{14} \mathrm{Y}_{2} \mathrm{C}_{15} \mathrm{~B}_{6}\right)$ utilizing the theoretical framework on viscous flow sintering.

The process of sintering involves a number of overlapping stages such as formation and growth of necks at the interparticle contacts, pore rounding, and pore closure [14]. Transport of mass during these stages takes place by various mechanisms one of which is usually dominant over the others, and primarily determined by the nature of the material [15]. For example, in amorphous materials, the principal mechanism of mass transport during sintering is viscous flow caused by the driving force of surface tension $[16,17]$. Studying the densification behavior of 
amorphous powder compacts during sintering enables identification and analysis of the various aspects of this mechanism. The instantaneous densification rate of the specimen, $\dot{\rho}_{n}\left(\mathrm{~s}^{-1}\right)$ is estimated according to [18]:

$\dot{\rho}_{n}=\frac{d \rho_{n}}{d t_{n}}=\frac{\rho_{n+1}-\rho_{n-1}}{t_{n+1}-t_{n-1}}$

where $\rho_{\mathrm{n}}(\%)$ is the instantaneous relative density at time $t_{n}(\mathrm{~s})$. The relative density, $\rho(\%)$ is calculated from the instantaneous height $L(\mathrm{~mm})$, initial height $L_{o}(\mathrm{~mm})$, and initial relative density $\rho_{o}(\%)$ as $[18]$ :

$\rho=\frac{L_{o}}{L} \rho_{o}$

The contribution of viscous flow to the isothermal shrinkage of a specimen can be expressed as [19]:

$\frac{\Delta L}{L_{o}}=\frac{3 \gamma}{4 D \eta} t$

where $\Delta L / L_{o}$ is the shrinkage of the powder, $\gamma\left(\mathrm{J} \mathrm{m}^{-2}\right)$ the surface energy, $D(\mathrm{~m})$ the average diameter of powder particles, and $\eta$ (Pa s) the coefficient of viscosity. Isothermal studies suffer from considerable drawbacks, the foremost among them being the lack of means for obtaining sintering shrinkage as a function of temperature through a single experiment [20]. In contrast, equations pertaining to isochronal (constant rate heating) studies accurately represent the brisk shrinkages that occur during initial stages of sintering cycles when thermal equilibrium is being attained. Moreover, these studies can effectively distinguish between different densification mechanisms with distinct activation energies in addition to being in better accord with industrial engineering practice [21]. In view of the above, the relationship between temperature and time in a isochronal experiment can be expressed as: 
$\frac{d T}{d t}=c$

where $T(\mathrm{~K})$ is the temperature and $c\left(\mathrm{~K} \mathrm{~s}^{-1}\right)$ is the constant rate of heating.

Over a small range of temperature the coefficient of viscosity of an amorphous material follows an Arrhenius equation [18]:

$\eta=\eta_{o} \exp \left(\frac{Q}{R T}\right)$

where $\eta_{o}(\mathrm{~Pa} \mathrm{~s})$ is the frequency factor, $Q\left(\mathrm{~J} \mathrm{~mol}^{-1}\right)$ the activation energy for viscous flow, and $R$ $\left(8.314 \mathrm{~J} \mathrm{~K}^{-1} \mathrm{~mol}^{-1}\right)$ the universal gas constant.

The shrinkage rate in isothermal conditions can be extended to isochronal ones by differentiating Eq. 3 with respect to temperature and applying Eqs. 4 and 5 as [18]:

$\frac{d\left(\frac{\Delta L}{L_{o}}\right)}{d T}=\frac{3 \gamma}{4 D c \eta_{o}} \exp \left(\frac{-Q}{R T}\right)$

Estimation of the slope of the shrinkage with respect to temperature, extremely sensitive to the measurement of the contraction, i.e., reduction of the thickness of the specimen, is affected by the resolution of data collection. Acquiring data according to Eq. 6 is also impeded by slight variation in the heating rate [20]. In order to circumvent this problem, Eq. 6 is integrated, assuming constant $\gamma, \eta_{\mathrm{o}}$ and $\mathrm{Q}$, resulting in, approximately:

$\frac{\Delta L}{L_{o}} \cong \frac{3 \gamma R T^{2}}{4 D c Q \eta_{o}} \exp \left(\frac{-Q}{R T}\right)$

Despite their gradual variation with temperature, the changes of the aforesaid parameters over small temperature intervals are negligible, and hence considered constant therein [20]. Both the differential (Eq. 6) and integral (Eq. 7) forms result in identical estimation of viscous flow 
parameters [21] and the latter shows that data relevant to $\left(\Delta \mathrm{L} / \mathrm{L}_{\mathrm{o}}\right) / \mathrm{T}^{2}$ when plotted, over a small range of temperature, in a semi-log plot should show a linear relationship with 1/T.

In the following, the above theoretical outline is applied to analyze the variations in instantaneous densification rate and activation energy for viscous flow with systematic increase of heating rate during SPS of Fe-based amorphous alloy powder. Gas atomized amorphous alloy powder of nominal composition $\mathrm{Fe}_{48} \mathrm{Cr}_{15} \mathrm{Mo}_{14} \mathrm{Y}_{2} \mathrm{C}_{15} \mathrm{~B}_{6}$ (at.\%) was used in the present investigation. It consisted of mostly spherical particles with a mean size of about $40 \mu \mathrm{m}$ [9]. About $3 \mathrm{~g}$ of this powder was sintered in a commercial SPS unit (Thermal Technology, Santa Rosa, USA) with graphite dies and punches inside a vacuum chamber to yield samples of diameter $15 \mathrm{~mm}$ and thickness about $2 \mathrm{~mm}$. A thermocouple placed inside the wall of the die was used for temperature measurement. Following prepressing under $25 \mathrm{MPa}$ pressure, the powder was sintered at heating rates of 50,100 , and $150{ }^{\circ} \mathrm{Cmin}^{-1}$ up to $1000{ }^{\circ} \mathrm{C}$ while maintaining pressure constant. During sintering, temperature, pressure and punch position were recorded with time and utilized for calculating powder contraction (reduction in thickness of the powder compact), densification rate, and shrinkage.

As shown in Fig. 1, the powder compact underwent an initial contraction of $1.2 \mathrm{~mm}$ followed by an additional $0.4 \mathrm{~mm}$ in two discrete stages of densification during SPS up to 1000 ${ }^{\circ} \mathrm{C}$ at each heating rate. Minute variations existed in the mass of powder poured into the die and consequently the values of $\rho_{o}$ utilized for estimating $\dot{\rho}_{n}$ during SPS at different heating rates were 54, 59, and $60 \%$ at 50, 100, and $150{ }^{\circ} \mathrm{Cmin}^{-1}$, respectively. The instantaneous densification rate was plotted according to Eq. 1 with the time interval $t_{n+1}-t_{n-1}$ as $2 s$, at different heating rates (Fig. 2). While a distinct trend in the densification rate is evident upon a systematic increase in heating rate during stage I, the same cannot be said about stage II. The characteristics of the 
former, such as the temperatures at which onset of densification $\left(T_{s}\right)$, peak densification rate $\left(T_{p}\right)$ and end of densification $\left(\mathrm{T}_{\mathrm{f}}\right)$ occurred are observed to shift to lower values while there is a steady increase in the peak densification rate $\left(\dot{\rho}_{p}\right)$ as the heating rates increased (Table 1).

The increase in densification rate during stage I with the rate of heating was subjected to further investigation. The glass transition temperature, $T_{g}$ of this alloy measured at a heating rate of $20{ }^{\circ} \mathrm{Cmin}^{-1}$ is $575{ }^{\circ} \mathrm{C}$ [3] which is expected to increase at higher heating rates as applied here $[22,23]$. The maximum densification rate during SPS at 50,100 , and $150{ }^{\circ} \mathrm{Cmin}^{-1}$ was attained at 549,484 and $441{ }^{\circ} \mathrm{C}$ respectively all of which are below the $\mathrm{T}_{\mathrm{g}}$ where the material remains in its glassy state. Indeed, the x-ray diffraction (XRD) analysis of samples sintered at these temperatures with respective heating rates exhibited a diffused halo (inset, Fig. 2) characteristic of fully amorphous materials. Thus during SPS at each heating rate, in the entire range from respective start temperature to peak temperature in stage I, the sample is fully amorphous suggesting the occurrence of viscous flow $[16,17]$. In contrast during SPS at $700{ }^{\circ} \mathrm{C}$ and above in stage II at all heating rates, the samples are fully crystalline as shown by a representative XRD spectrum (inset, Fig. 2). The parameter $\left(\Delta \mathrm{L} / \mathrm{L}_{\mathrm{o}}\right) / \mathrm{T}^{2}$ plotted with respect to $1 / \mathrm{T}$ shows a linear behavior in the temperature ranges 447 to $549{ }^{\circ} \mathrm{C}, 345$ to $484{ }^{\circ} \mathrm{C}$ and 323 to $441{ }^{\circ} \mathrm{C}$ at the heating rates of 50, 100 and $150{ }^{\circ} \mathrm{Cmin}^{-1}$ respectively (Fig. 3). In view of the limitations of measurement noted previously and the approximate form of Eq. 7, this confirms the mechanism of mass transport to be viscous flow. The activation energy for viscous flow are estimated from the slopes according to Eq. 7, in these small temperature intervals, to be $76.2 \pm 0.4,64.0 \pm 0.9$, and $55.2 \pm 1.0 \mathrm{~kJ} \mathrm{~mol}^{-1}$ at heating rates of 50,100 , and $150{ }^{\circ} \mathrm{Cmin}^{-1}$, respectively.

Although, the $T_{g}$ of a bulk metallic glass increases with heating rate, the viscosity below the $T_{g}$ reduces due to irreversible relaxation of structure. This is quantitatively explained by the 
directional structural relaxation (DSR) model [24], where the viscosity of a bulk metallic glass at a given temperature below the $T_{\mathrm{g}}$, is inversely proportional to the heating rate [25]. Assuming $\eta_{o}$ to be independent of the heating rate, the activation energy evaluated at a given temperature should decrease logarithmically as the heating rates are increased. Although in the present study a single temperature where the activation energy can be examined for all heating rates cannot be obtained, its variation over small temperature intervals are negligible. In view of this, the gradual reduction in activation energy for viscous flow with increasing heating rate does indicate considerable agreement with the DSR model. However, further analysis of the dependence of the viscosity of this amorphous alloy powder with temperature during spark plasma sintering, a prime focus of our ongoing investigations, is necessary to establish a cogent conclusion.

To synopsize, the intrinsic role of high heating rates on the shrinkage behavior of $\mathrm{Fe}_{48} \mathrm{Cr}_{15} \mathrm{Mo}_{14} \mathrm{Y}_{2} \mathrm{C}_{15} \mathrm{~B}_{6}$ amorphous alloy powder was examined by analyzing the operating mechanism of densification during isochronal SPS. The sintering of the specimens took place in two successive, clearly distinguishable stages of densification, namely stage I, during which the sample remained mostly amorphous and stage II, during which it was completely crystalline. Additionally, they manifested a conspicuous reduction in the temperature at which the onset of densification occurred during the first stage with an increase in the heating rate. The densification rate also increased, attaining their corresponding, progressively higher, peak values at systematically lower temperatures. The enhanced densification rate reduced the driving force leading to a gradually earlier end of stage I sintering. Viscous flow was confirmed to be the mechanism of densification in the entire range from respective temperatures of onset densification to that of attainment of peak densification rate at each heating rate. The activation energy for viscous flow underwent a steady reduction leading to the observed enhancement of 
densification rate during sintering with higher heating rates while exhibiting considerable agreement with the DSR model.

\section{Acknowledgements}

This material is based upon work supported by the National Science Foundation under Grant No.

CMMI-1462602. 


\section{References}

[1] P. Guyot, G. Antou, N. Pradeilles, A. Weibel, M. Vandenhende, G. Chevallier, A. Peigney, C. Estournes, A. Maitre, Scripta Mater. 84-85 (2014) 35-38.

[2] Z.A. Munir, U. Anselmi-Tamburini, M. Ohyanagi, Journal of Materials Science 41(3) (2006) 763-777.

[3] S.P. Harimkar, S.R. Paital, A. Singh, R. Aalund, N.B. Dahotre, J. Non-Cryst. Solids 355(4344) (2009) 2179-2182.

[4] O.A. Graeve, M.S. Saterlie, R. Kanakala, S. Diaz de la Torre, J.C. Farmer, Scripta Mater. 69(2) (2013) 143-148.

[5] X. Li, G. Lu, Z. Zhang, D. Ju, A. Makino, J. Alloys Compd. 647 (2015) 917-920.

[6] B.V. Neamtu, T.F. Marinca, I. Chicinas, O. Isnard, F. Popa, P. Pascuta, J. Alloys Compd. 600 (2014) 1-7.

[7] A. Inoue, K. Hashimoto, Amorphous and Nanocrystalline Materials: Preparation, Properties and Applications, Springer, Berlin 2001.

[8] N. Chawake, L.D. Pinto, A.K. Srivastav, K. Akkiraju, B.S. Murty, R.S. Kottada, Scripta Mater. 93 (2014) 52-55.

[9] A. Singh, T. Paul, S. Katakam, N.B. Dahotre, S.P. Harimkar, JOM 68(7) (2016) 1932-1937.

[10] O.A. Graeve, R. Kanakala, L. Kaufman, K. Sinha, E. Wang, B. Pearson, G. Rojas-George, J.C. Farmer, Mater. Lett. 62(17-18) (2008) 2988-2991.

[11] M.K. Mani, G. Viola, M.J. Reece, J.P. Hall, S.L. Evans, Mater. Sci. Eng. A 592 (2014) 1927.

[12] Z. Wu, X.a. Fan, G. Li, Z. Gan, J. Wang, Z. Zhang, Mater. Sci. Eng. B 187 (2014) 61-66.

[13] Y. Zhang, P. Sharma, A. Makino, AIP Advances 3(6) (2013). 
[14] R.M.German, Sintering: From Emperical Observations to Scientific Principles, Elsevier, MA, USA, 2014.

[15] G.C. Kuczynski, Transactions of the American Institute of Mining and Metallurgical Engineers 185(2) (1949) 169-178.

[16] G.C. Kuczynski, J. Appl. Phys. 20(12) (1949) 1160-1163.

[17] G.C. Kuczynski, I. Zaplatynskyj, J. Am. Ceram. Soc. 39(10) (1956) 349-350.

[18] L.H. Liu, C. Yang, Y.G. Yao, F. Wang, W.W. Zhang, Y. Long, Y.Y. Li, Intermetallics 66 (2015) 1-7.

[19] V.V. Dabhade, T.R.R. Mohan, P. Ramakrishnan, Mater. Res. Bull. 42(7) (2007) 1262-1268.

[20] I.B. Cutler, J. Am. Ceram. Soc. 52(1) (1969) 14-17.

[21] W.S. Young, I.B. Cutler, J. Am. Ceram. Soc. 53(12) (1970) 659-663.

[22] B. Movahedi, M.H. Enayati, C.C. Wong, Mater. Lett. 64(9) (2010) 1055-1058.

[23] P. Ramasamy, M. Stoica, A.H. Taghvaei, K.G. Prashanth, R. Kumar, J. Eckert, J. Appl. Phys. 119(7) (2016).

[24] V.A. Khonik, V.A. Mikhailov, I.A. Safonov, Scripta Mater. 37(7) (1997) 921-928.

[25] A.V. Lysenko, S.A. Lyakhov, V.A. Khonik, M.Y. Yazvitskii, Physics of the Solid State 51(2) (2009) 221-225. 


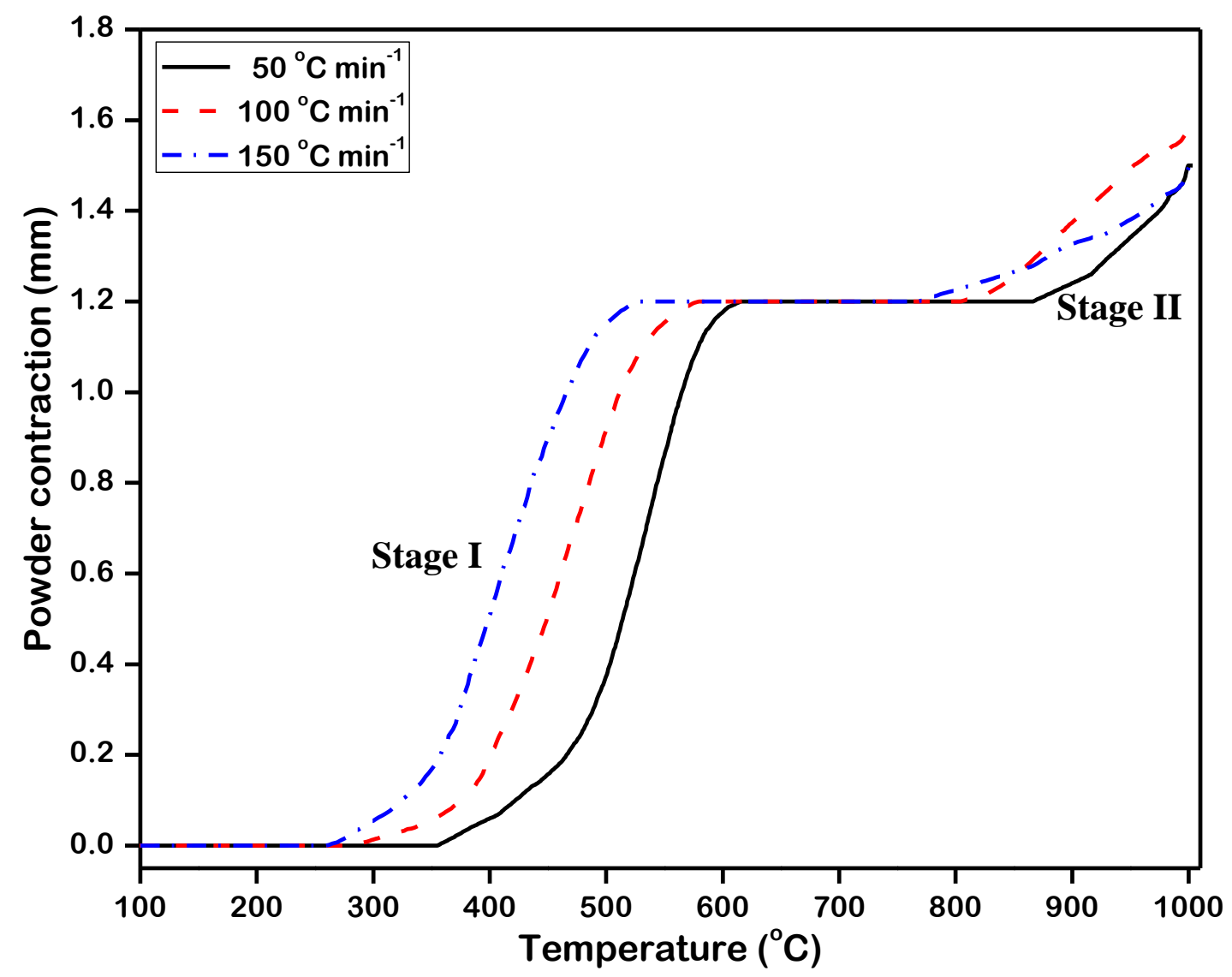

Fig. 1 Powder contraction of $\mathrm{Fe}_{48} \mathrm{Cr}_{15} \mathrm{Mo}_{14} \mathrm{Y}_{2} \mathrm{C}_{15} \mathrm{~B}_{6}$ amorphous alloy during SPS at heating rates of 50,100 , and $150^{\circ} \mathrm{Cmin}^{-1}$ 


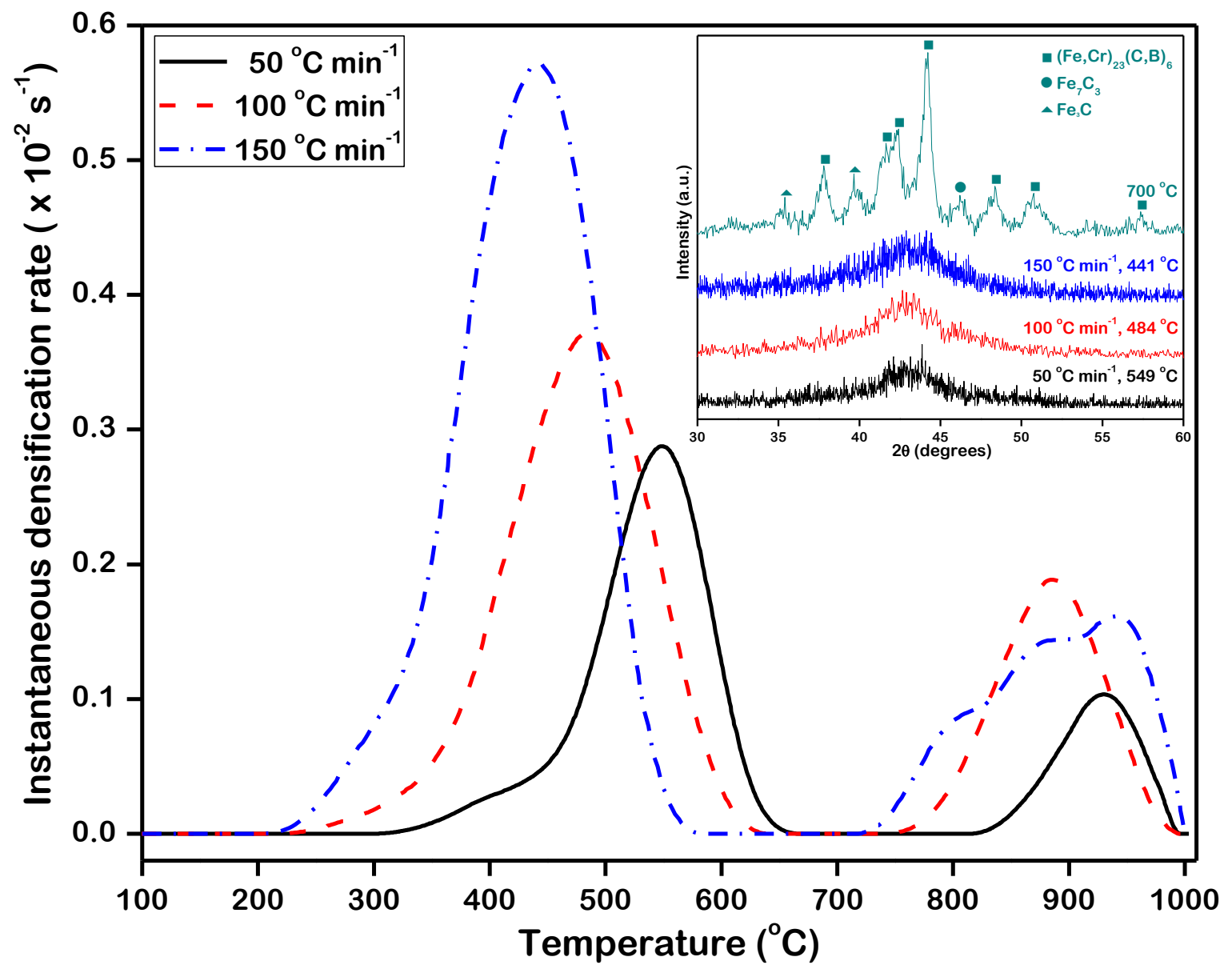

Fig. 2 Instantaneous densification rate during SPS at heating rates of 50,100, and $150^{\circ} \mathrm{Cmin}^{-1}$. Inset depicts XRD spectra of specimens $\mathrm{SP}$ sintered upto $\mathrm{T}_{\mathrm{p}}$ at respective heating rates and representative specimen SP sintered at $700{ }^{\circ} \mathrm{C}$ 


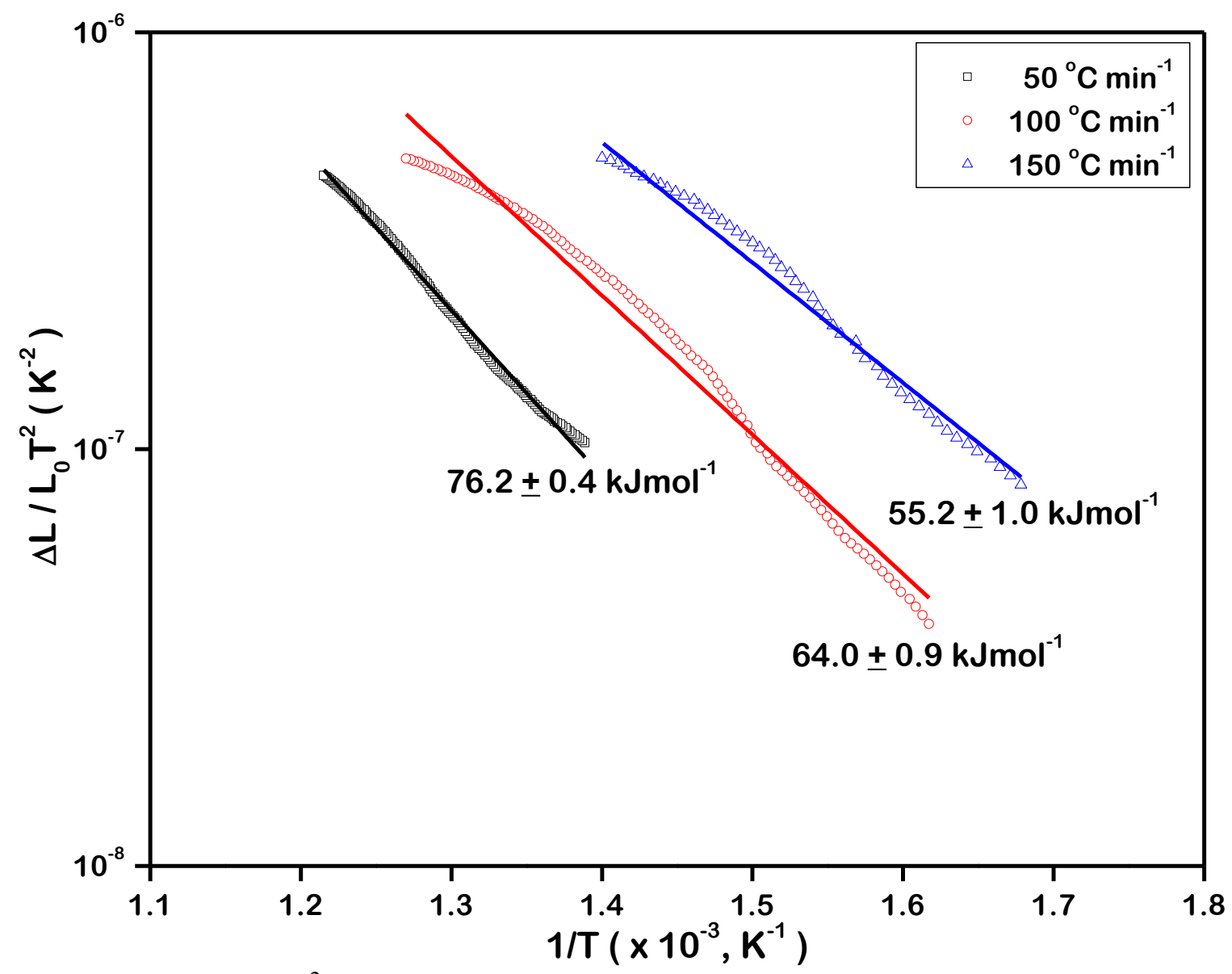

Fig. 3 Plot of $\left(\Delta \mathrm{L} / \mathrm{L}_{\mathrm{o}}\right) / \mathrm{T}^{2}$ for the powder according to Eq. 7 corresponding to stage I densification. The estimated activation energies at heating rates of 50,100 and $150^{\circ} \mathrm{Cmin}^{-1}$ are indicated 
Table 1. Characteristics of stage I

densification at different heating rates

\begin{tabular}{ccccc}
\hline $\begin{array}{c}\mathrm{c} \\
\left({ }^{\circ} \mathrm{Cmin}^{-1}\right)\end{array}$ & $\begin{array}{c}\mathrm{T}_{\mathrm{s}} \\
\left({ }^{\circ} \mathrm{C}\right)\end{array}$ & $\begin{array}{c}\mathrm{T}_{\mathrm{p}} \\
\left({ }^{\circ} \mathrm{C}\right)\end{array}$ & $\begin{array}{c}\mathrm{T}_{\mathrm{f}} \\
\left({ }^{\circ} \mathrm{C}\right)\end{array}$ & $\begin{array}{c}\dot{\rho}_{p} \\
\left(\mathrm{~s}^{-1}\right)\end{array}$ \\
\hline 50 & 300 & 549 & 667 & 0.0029 \\
100 & 221 & 484 & 641 & 0.0037 \\
150 & 205 & 441 & 582 & 0.0057 \\
\hline
\end{tabular}




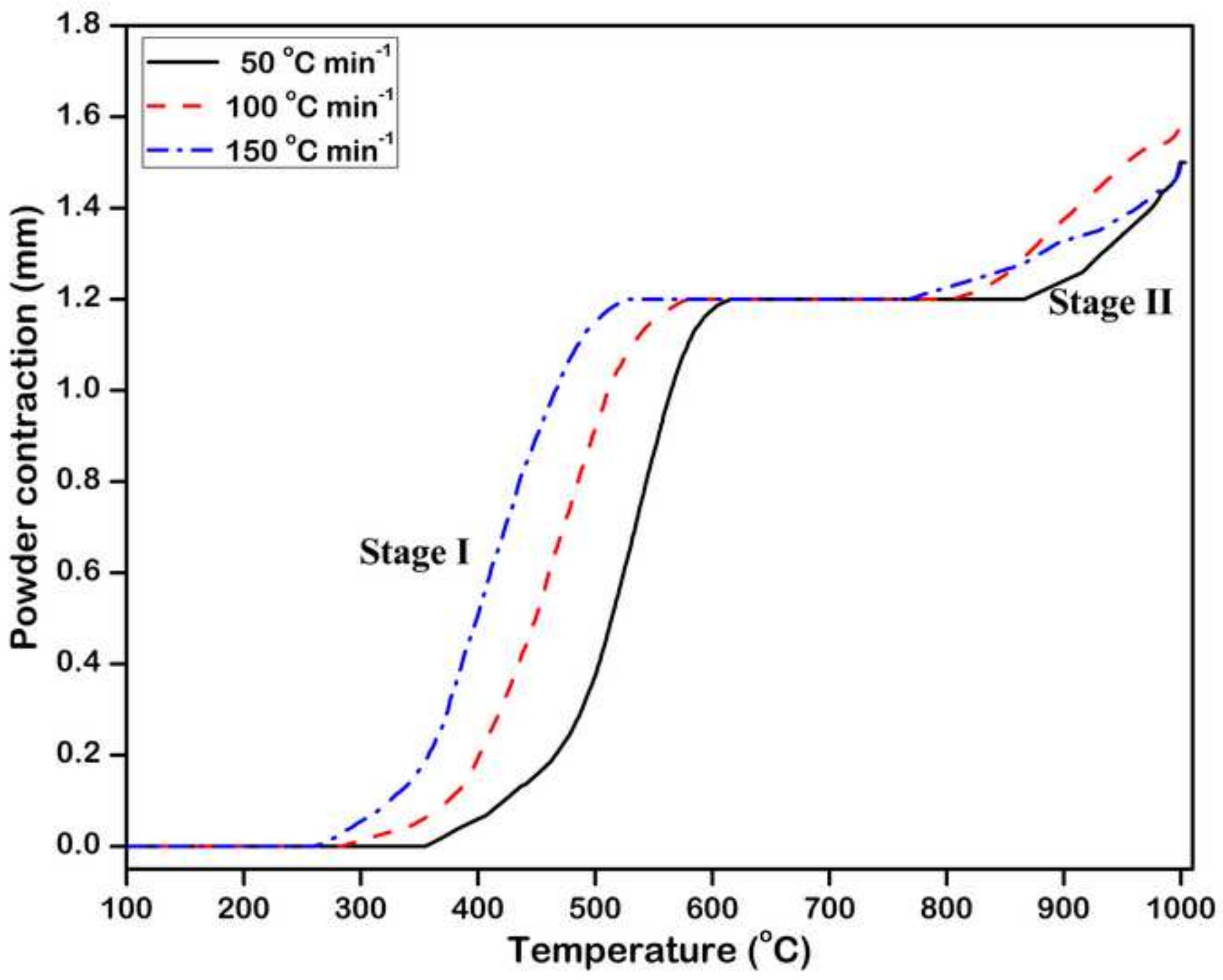




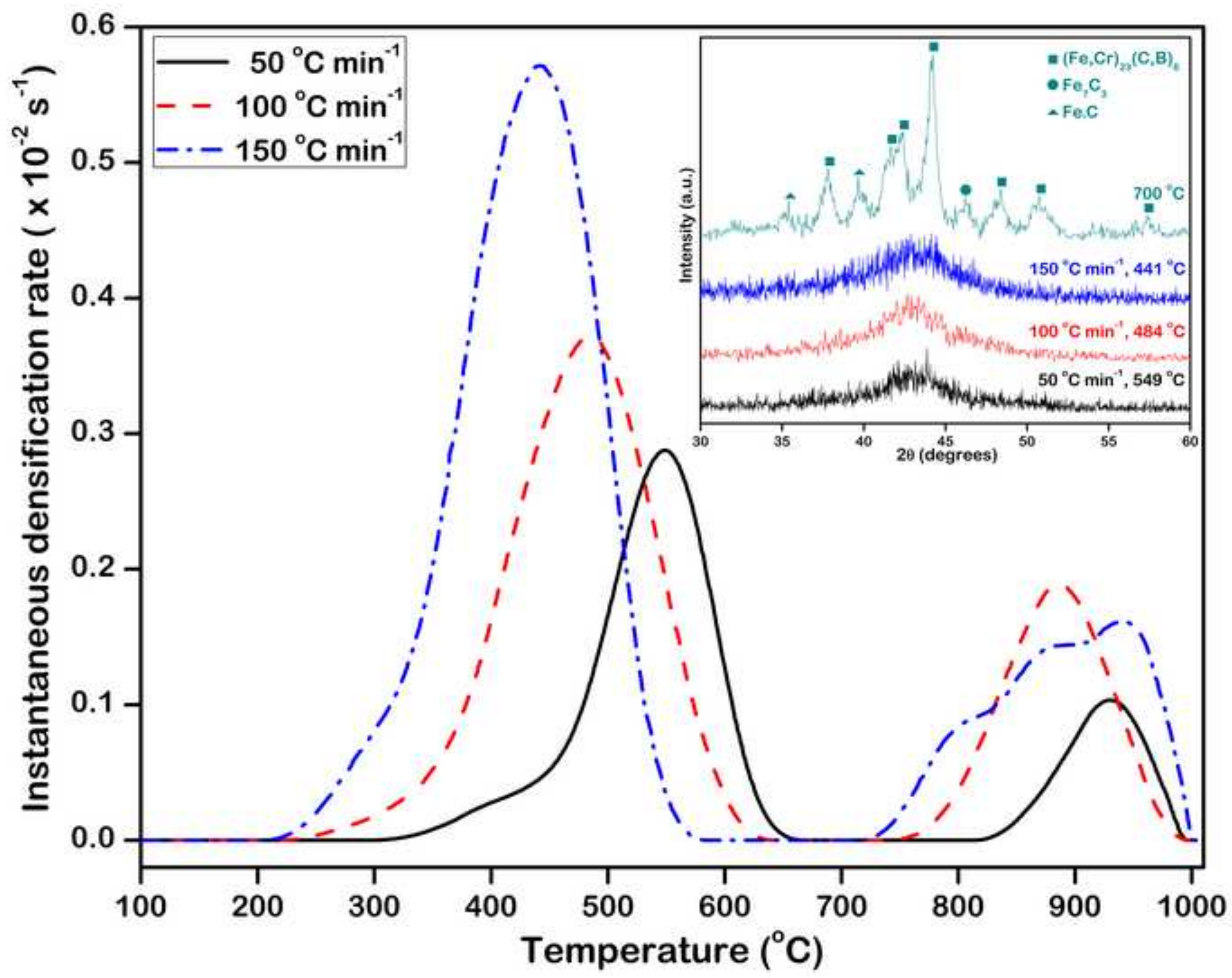




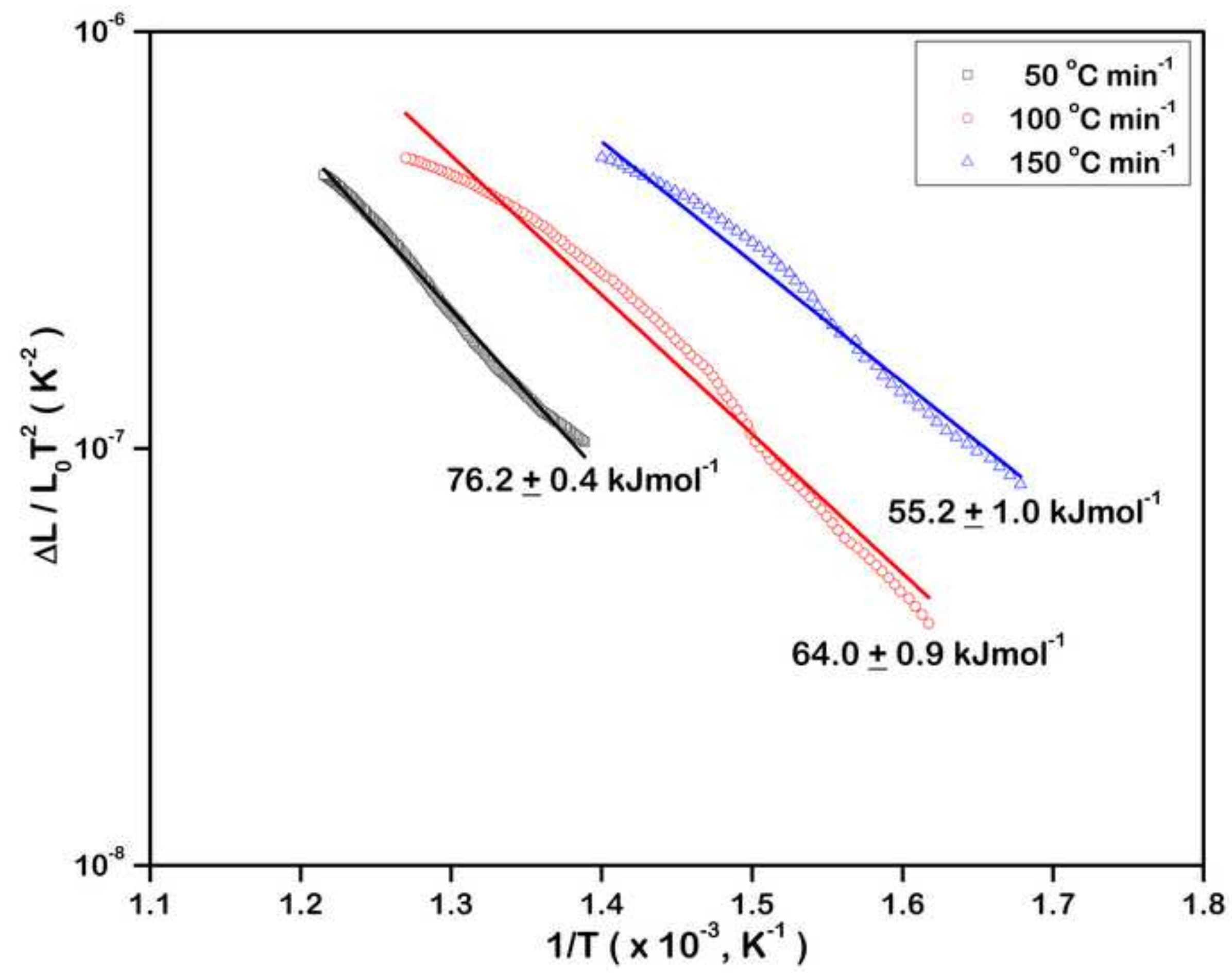



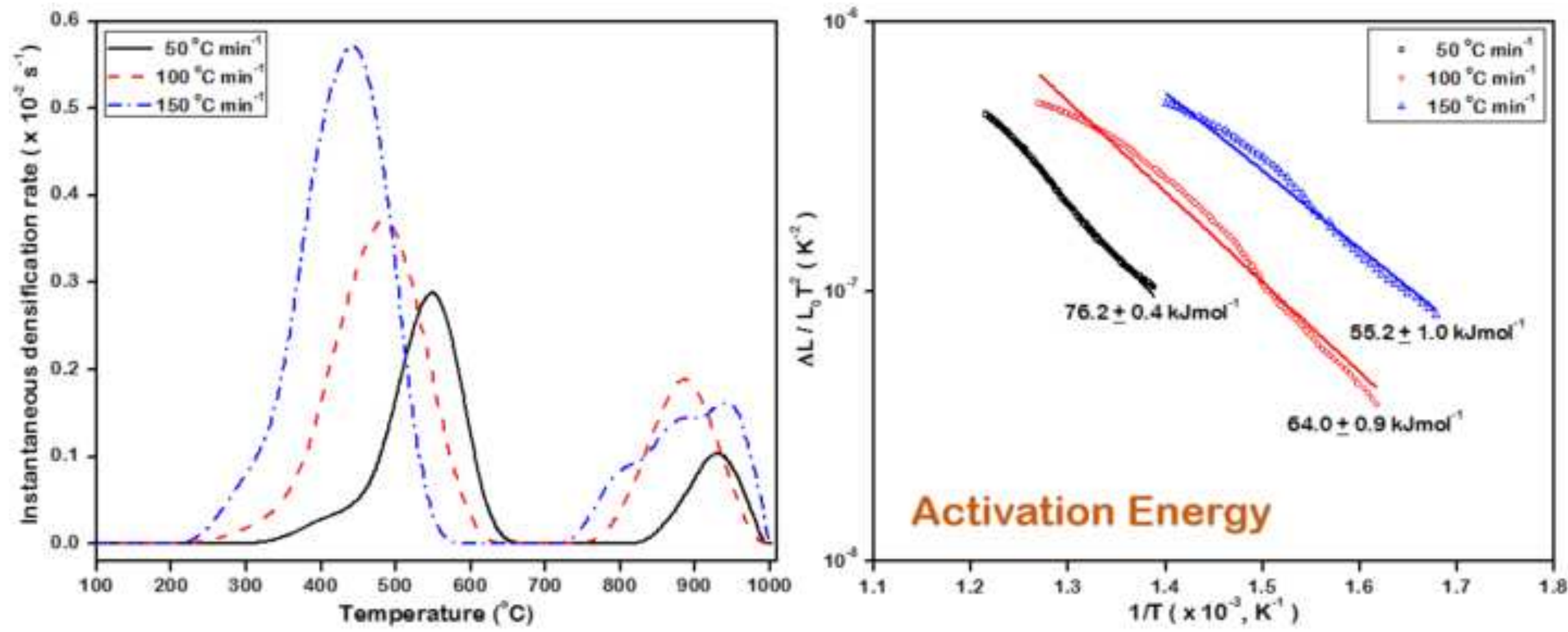